\title{
Correction to: Is the Spanish Constitutional Court an instrument of the central government against the Autonomous Communities?
}

\author{
Julio López-Laborda ${ }^{1}$ - Fernando Rodrigo ${ }^{1}$ - Eduardo Sanz-Arcega ${ }^{2}$
}

Published online: 18 November 2017

(C) Springer Science+Business Media, LLC, part of Springer Nature 2017

\section{Correction to: Const Polit Econ \\ https://doi.org/10.1007/s10602-017-9250-1}

The original version of this article unfortunately contained a mistake. An entry was missing in the explanatory variable. The missing "VAL/CRISIS/CAT" entry is given below:

VAL/CRISIS/CAT: Correspond, respectively, to the ruling of the TC on the Statute of Autonomy of the Autonomous Community of Valencia (12 December 2007), the start of the economic crisis (second quarter of 2008) and the TC ruling on the Statute of Catalonia (27 June 2010). These events are usually associated with a greater pull towards centralisation by the CG. Consequently, if the rulings are more favourable to the ACs after these dates, the alternative hypothesis can be accepted $(-)$.

The original article can be found online at https://doi.org/10.1007/s10602-017-9250-1.

Eduardo Sanz-Arcega

eduardosanzarcega@gmail.com

1 University of Zaragoza, Saragossa, Spain

2 University CEU San Pablo, Madrid, Spain 